\title{
ICT Integrated Pedagogy in a Multicultural Classroom: Experiences of Mathematics Teacher
}

\author{
Lok Nath Bhattarai \\ Lecturer \\ Central Department of Education (Mathematics) \\ Tribhuvan University, Kathmandu, Nepal \\ Email: lnbhattarai9@gmail.com
}

\begin{abstract}
Multiculturalism in the present context is a global issue in education. It has not yet been materialized into the education system in Nepal. The education system of a country should prepare students to function in today's multicultural society. In this regards, this paper focuses on the issues of the management of multicultural classes, and the role of ICTintegrated pedagogy to manage such a classroom context. It also discusses the context, and experiences of teachers that can bring the multicultural classroom situation into the right track. For this purpose, I apply narrative inquiry of two mathematics teachers (one male and one female) of University Campus Kirtipur with more than seven-year experience. In-depth interview, related to their experiences and practices in multicultural mathematics classes, was conducted and found that they face problems to teach students in a multicultural classes such as language problem, content problem, and level of understanding. There are two types of multiculturalism in our classes they are critical multiculturalism, and Liberal multiculturalism. The management of multiculturalism is a great challenge for teachers. Although teachers are less familiar with the management of multicultural class, they try to manage such types of diversity by supporting their students personally through ICT-integrated pedagogy. The finding of the study shows that ICTintegrated pedagogy is the best strategy to manage multicultural classes by respecting students' personal feelings.
\end{abstract}

Keywords: Multicultural classes, connectivism, liberal multiculturalism, ICT integrated pedagogy, narrative inquiry

\section{Background of the Study}

Twenty-first century is the era of information and communication technology (ICT). Now there is possibility of using ICT both as content and as a method. One of the purposes to introduce ICT in education is support effective learning. The pedagogical rationales of using ICT are to utilize technological tools in enhancing learning, flexibility and efficiency in curriculum delivery (Ghosh, Hattangdi and Atonu, 2007). Use of ICT-integrated pedagogy can transform the dynamics in math classes, making the lectures integrated to practice and providing resources that help in securing content and approach of theory with everyday life. ICT can be used in a mathematical laboratory 
that help develop intuition, conjecture, prove, show and "see the mathematical situations" in a practical way. For this, ICT has become a valuable teaching tool, offering great possibilities to education. It can produce significant changes in teaching methods and the way in which students can access and interact with the mathematical knowledge (Hofmann, 2006).

Teachers must be knowledgeable and sensitive to multicultural issues. They must have understanding of today's diverse student population and must avoid cultural generalization. In cases of such cultures in which teacher lacks knowledge, he must bring resource persons to help students understand this culture properly. Opportunities should be given to the students to share their own cultural experiences. In this way, a teacher needs to address the issues related to each of the students' culture so that the students feel his/her importance and freely contribute to classroom discussions. This will lead students join hands with the other students and help to develop a classroom community. The students develop a feeling of 'our classroom'. The students must be taught how to live together interacting in meaningful ways without dominating each other so that they learn how to work together to survive on this planet.

\section{Common Perception on Multiculturalism}

The culture of the mathematics classroom, which was brought to our attention as being significant (Nickson, 1992), is not monolithic or static but continuously evolving, and different in different classrooms as these norms become negotiated. The mathematics classroom itself is one area in which culture is contested, negotiated, and manifested (Vithal, 2003), but there are various levels of scale. These are the cultural, the societal, the institutional, the pedagogical, and the individual aspects. Culture, here is viewed as an all-encompassing umbrella construct that enters into all the activities of humans in their communicative and social enterprises. In addition to a view of culture in this macroscopic aspect, as in these levels of scale, culture as webs of significance may be central also in the societal, institutional, and pedagogical aspects of mathematics education considered as a social process. Thus researchers may speak of the culture of a society, of a school, or of an actual classroom. Culture in all of these levels of scale impinges on the mathematical learning of individual students.

Multiculturalism is closely associated with "identity politics," "the politics of difference," and "the politics of recognition," all of which share a commitment to revaluing disrespected identities and changing dominant patterns of representation and communication that marginalize certain groups (Gutmann 2003, Taylor 1992, Young 1990). Multiculturalism involves not only claims of identity and culture as some critics of multiculturalism suggest. It is also a matter of economic interests and political power: it includes demands for remedying economic and political disadvantages that people suffer as a result of their marginalized group identities.

\section{Statement of the Problem}

Nepal is a multicultural, multiethnic, and multilingual country. Nepal has a hierarchical society structure. Teachers face with the challenges of teaching students from multicultural background. The classrooms represent Sherpa students of Mountain region to Madhesh of Terai. The students come from various religious backgrounds Hindu, Buddhist and Muslim. Multicultural education is quite complex to define since there is no universally accepted definition for it. Multicultural 
education can be broadly defined as education, which is usually formal, and in which two or more cultures are involved. Multicultural education involves the educational policies and practices which are linked to school's goals in order to meet the separate educational needs of various groups of pupils. It is important to consider the cultures and traditions of these groups. It requires that minorities learn about majorities and other minorities and majorities learn about minorities. Learning here means learning about culture and traditions. Flourishing cultural diversity and social equality is thus a goal for multiculturalism (Talib, 2006, p. 141).

To manage the multicultural nature of students, the new developing concept towards teacher's behavior assumes teacher as the facilitator who only facilities the students only at their difficulties. In fact learning is the human activity which at least needs manipulation by the others (Clement, 1982). Most learning is not the result of the instruction. It is rather the result of the unhampered participation in a meaningful setting (Frere, 1968). Are teachers able to create such meaningful environment? Are teachers providing such situation so that the students are able to learn according to their pace and capacities? Are teachers able to address the interest and learning capacity of students from different culture, different socioeconomic status and different gender? These are today's questions and challenges to the teachers.

If ICT integrated pedagogy works as expected the student who do not get chance to attain their regular classes will not miss their mathematics classes as well as each students will have opportunity to understand any concepts at their own pace. Information communication technology integrated pedagogy is defined as the teaching learning process and environment where the students have the access of getting /having the teacher's class presentation as a learning aid at their needs with flexibility of time and space. Students can view the teacher's class presentation at their home using ICT tools and using this they can solve the assigned problems themselves at home. Hence the ICT integrated pedagogy will be the best strategies to manage the diversity of mathematics class effectively. In this context, the study to find the experience of mathematics teacher about the management of multiculturalism is essential. So the researcher intends in this area.

In short, this research explores the following research questions:

1. How do teacher experience teaching mathematics in multicultural classroom taught by ICTintergrated pedagogy?

2. How can teachers manage multiculturalism effectively in mathematics classes?

\section{Objectives of the Study}

The prime concern of this study was to investigate the experience of teachers in teaching mathematics on multicultural classroom by applying ICT-integrated pedagogy in semester classes. More specifically, it aimed at finding the experience of teachers and learning style of students in multicultural classroom. Similarly, this study also tried to describe the role of ICT integrated pedagogy to manage multicultural classes. 


\section{Theoretical Understanding}

A number of scholars have provided theoretical insights about the management of multicultural mathematics classes by using ICT integrated pedagogy and teachers experience, children's struggles and under achievement in multicultural classes. In this research I review some literatures and discuss some theories that support the management of multiculturalism in mathematics classes from teachers' point of view as well as learning style of students from different culture and select two major theories in my study. The theories that I discuss here are theories of multicultural education and connectivism theory.

The first theory that I discuss here is multiculturalism in education. The traditional perspective in education is referred to as conservative multiculturalism. Conservative multiculturalism theory defines multiculturalism as a dividing factor and argues that the conventions and norms of the dominant culture should be internalized (Grant and Ham, 2013). Conservative multiculturalists tend to view culture as a fixed, essentialist and a pre determined entity (Hopkins-Gillispie, 2011; Taguieff, 1997). According to conservative multiculturalists, the world is 'as it is' (HopkinsGillispie, 2011). Liberal multiculturalism accepts that all ethnic and racial groups naturally are equal and the same "intellectually" (McLaren, 1995).

Liberal multiculturalism starts with respect for cultural and ethnic differences, supports cultural sensitivity in curriculum and instruction and cherishes cultural traditions (Banks, 2010; Gay, 2000; Martin, 1998). According to Grant (1994), liberal multicultural education suggests that learning styles, learning strategies, schools and parents be integrated to the educational program. Most teachers who apply practices of liberal multiculturalism feature some aspects of cultural diversity (for example religious differences) in their educational practices and support bilingual education. In this approach, teachers teach content that also includes other cultures. Teachers should be ready to understand students with diverse backgrounds and learn how to communicate with parents. Liberal multicultural perspective considers culture to be dynamic and flexible as opposed to conservatives who deem it fixed and essentialist. According to liberal multiculturalists, the world can be different (Gillispie, 2011).

Similarly, another type of multiculturalism is critical multiculturalism. Critical multicultural education theory expands on the educational program and instruction focused on by liberal multiculturalism and emphasizes the need for a structural change. It provides a cultural framework and context as to how unequal power relations are maintained at a structural and institutional level in daily interactions (May and Sleeter, 2010, 10). Sleeter and Grant (2006) criticize modern society and state that the pressure one group builds on others should be eliminated and educational programs should be entirely restructured to reflects the concerns of different cultural groups. This perspective states that educational practices educational programs, class management and support for a normal class - that consider the needs of all students are possible and suggests that diversity should be considered in as many aspects as possible. This perspective emphasizes the importance of the participation of students in school wide decision making processes, the participation of low social group and minority parents, the participation of schools in local social action projects and the participation of nontraditional groups such as those from different races and genders as well as the disabled (Sleeter and Grant, 2006). 
In my study the theories of multicultural education is applied in two ways: one of them is educational practices, educational programs, class management and supports for students should be manage according to the needs of all students. Similarly it suggests that diversity should be considered as many aspects as possible through the active participation of students by experiencing the successful completion of the challenging tasks. The second is the role of teacher as a facilitator and assume that all ethnic and racial groups naturally are equal and the same intellectual capacity at the process of teaching.

Similarly, the second theory I applied in this study is connectivism. Connectivism also offers the specific technological opportunities for the learner to be actively involved in the presentation of a body of knowledge. Siemen proposed connectivism as an alternative learning which states that learner attempt to foster understanding connection between specialized communities (Duke, Harper and Johnoton, 2006).

Connectivism could be a learning theory for the following reasons: First, connectivism is characterized as the enhancement of how a student learns with the knowledge and perception gained through the addition of a personal network (Siemens, 2004). Being able to tap into huge databases of knowledge in an instant empowers a learner to seek further knowledge. Such a capacity to acquire knowledge can facilitate research and assist in interpreting patterns. Second, explaining learning by means of traditional learning theories is severely limited by the rapid change brought about by technology. Connectivism is defined as actionable knowledge, where an understanding of where to find knowledge may be more important than answering how or what that knowledge encompasses.

In this study the Connectivism is applied in two ways: one of them is teacher will empower learner and facilitate them by interpreting patterns. Second, use ICT integrated pedagogy to address multiculturalism in mathematics teaching.

\section{Research Design}

This study adopted qualitative research design in order to find the experiences of mathematics teachers on the implementation of ICT integrated pedagogy in multicultural classes since it would be possible to obtain rich and in-depth data. The generalization was not the main aim of the study and it was confined to two mathematics teachers of University Campus.

I adopted narrative inquiry research design of qualitative research approach in this study. According to Webster and Mertov (2007, p.1),"narrative inquiry provides researchers with a rich framework through which they can investigate the ways humans experience the world depicted through their stories". Similarly, Khanal (2009, p.241) said, "Narrative inquiry is the process of gathering information for the purpose of research through story telling ". Thus, I employed narrative inquiry to collect the experiences of mathematics teachers to teach mathematics through ICT integrated pedagogy in multicultural mathematics classes.

\section{Informants}

The informants of the study includes a total of two mathematics teachers ( 1 female, 1 male) who were teaching in University Campus kirtipur. They were selected following a purposive and convenience sampling technique. The informants had more than seven years of teaching 
experience and all voluntarily participated in this research (Cakmak, 2013). In detail, teachers between seven and fifteen years of teaching experience were participated in the research. Teachers' subject area was mathematics education from same department. To ensure anonymity, alpha-numeric identity (T1\& T2) had been used for the participants involved in this study (Ambler, 2016).

\section{Data Collection}

Interview technique was used to collect data in this study. The interview, being the most common and powerful research method, enables participants to speak for themselves. The semi-structured interview was used in order to elicit in depth data from the mathematics teachers on their perception, practice and beliefs about experience of teaching with ICT integrated pedagogy in multicultural mathematics classes in central department of education TU.

\section{Data Analysis}

The experience of teachers on teaching multicultural mathematics through ICT integrated pedagogy which was obtain from interview was interpret by using general inductive method as described by Thomas (2006). All interviews were first audio-recorded by the researcher by taking the informants' permission. Secondly, data was transcribed for analyzing process. Thirdly, content analysis was utilized based on the assigned codes, basic themes, organizing themes and global theme on the text. Finally, the global themes were defined in terms of the basic themes, organizing themes and codes given (as cited in Cakmak, 2013).

\section{Findings and Discussions}

In this part of the study, findings and discussions are given under several subtitles with the following sequence: Teachers experiences in teaching multicultural classes and Management of multiculturalism through ICT integrated pedagogy.

\section{Teachers' experiences in teaching multicultural classes}

Teaching mathematics with the students from different intellectual level, different socioeconomic background, different community, different culture and different interest groups is exciting because there is new environment and all circumstances are different for the teachers. When the teachers enters into the class to teach, they reflect that what they experienced in their previous classes and social context. The multiculturalism in mathematics class room and its management is a great job for teachers. We teachers are always experience multicultural classroom context in our daily job. In this regard T1, one of my informants, said;

There are many challenges for teaching mathematics in diverse situation. Firstly, the differences in culture are an aspect of personality, which needs to be crossed in order to be an effective teacher. This, however, takes effort from the side of teacher and creates additional work in teaching process. I, as a teacher always try to manage students from different culture and different intellectual level but due to large class size and time constraints we are not completely satisfied for our purpose. Secondly, the students have different individual interest, learning style and poor prerequisite knowledge on the subject matter that is really a challenging for us. The use of ICT integrated pedagogy sometime facilitate such problems. 
As the remarks expressed by T1 what I feel that teaching in multicultural classroom requires a lot of additional effort from the teacher, since he or she has to pay attention more carefully that everyone is able to follow the classroom instruction. Even though cultural awareness is important for teachers but how can it possible for a single teacher? Also, different students have different interest due to individual difference and the teacher must choose the best strategies to manage such problem. Regarding this matter, Duke, Harper and Johnoton (2006) asserted that connectivism offers the specific technological opportunities for the learner to be actively involved in the presentation of a body of knowledge and it will be an alternative learning strategies which states that learner attempt to foster understanding connecting between specialized communities. On the other hand, many students in the mathematics class have very poor prerequisite knowledge that creates problem to run the class smoothly. The large class size and time constraints for teachers as well as students also creates problem for effective mathematics teaching. But, after listening to the opinion of my first participant what I realize that the ICT integrated pedagogy helps to manage the large class size and multicultural issue in mathematics class. It is also supportive for the effective mathematics teaching. In the same issue, T2 expressed his ideas as,

Every teacher have a strong commitment and willpower to manage the multicultural classes. I always pay attention for the individual difference of students. I encourage all the students to participate in their classes actively and provide extra guidance as their necessity. Many of my students request me for the supportive materials through my personal email, Viber and personal phone contact also, then I provide them the necessary information without any hesitation. This type of individual support helps to manage the multicultural mathematics classroom. We need training to develop the skill for the management of multicultural classroom such that we can make our class effective.

As the remarks expressed by T2 what I feel that teacher should manage good classroom environment by providing equal opportunity to their students. Regarding these views, Guba and Lincoln (2001) stated "learner has active role in the process of knowledge construction and child learn through the interaction with the friends. They learn by experiencing the successful completion of the challenging tasks". The account expressed by my second participant above indicated that the teacher must respect the individual differences of students and engage them in class work as well as project works. Teacher's commitment and effort make mathematics class more interactive as well as productive. As my second participant, multicultural theory of education also assumes teacher as a facilitator at the process of teaching and learning. The personal support of teachers helps to reduce individual differences of the class.

The above view of teachers indicate that the provision of technological aspect of course content about the multiculturalism in Master's level course on TU is not sufficient. ICT integrated pedagogy in the context of mathematics learning is increasing day by day. In the present context, many research found that there is possibility of using ICT both as content and as a method. One of the purposes to introduce ICT in education is pedagogical improvement. The pedagogical rationales are to utilize technology in enhancing learning, flexibility and efficiency in curriculum delivery (Ghosh, Hattangdi and Atonu, 2007). ICT can enhance the greater collaboration between 
the pupils as it helps to increase students" motivation towards the teaching ("becta", 2014). ICT also has the potential to offer valuable support to teachers of different Levels. Teachers have bitter experiences and reflection on the management of diversity by using modern technology on their classroom in the sense that they don't know how to use modern technology in the classroom. Many teachers do not get to participate on any orientation and training.

\section{Management of multiculturalism through ICT integrated pedagogy}

In the context of Nepal, teachers and students are very much curious and optimist towards the use of ICT in mathematics online classes but the limited resources is the main huddle for the effective implementations. On the other hand in our classroom, different students have different interest due to individual difference and the teacher must choose the best strategies to manage such problem. Regarding this matter, Duke, Harper and Johnoton (2006) asserted Connectivism offers the specific technological opportunities for the learner to be actively involved in the presentation of a body of knowledge and it will be an alternative learning strategies which states that learners attempt to foster understanding connecting between specialized communities. In the support of teachers views, Ghosh, Hattangdi and Atonu, 2007, Becta, 2014 says, ICT can enhance the greater collaboration between the pupils as it helps to increase students' motivation towards the teaching. Every teacher wants to manage the multiculturalism in a class and made his teaching learning productive but most of them fail to manage it. In this regard one of my participants, T2 says;

"The most effective ways to manage multicultural mathematics class is the use of ICT integrated pedagogy in teaching learning process. There is misconception about the use of ICT integrated pedagogy in mathematics class due to lack of knowledge even though it is very effective to address the individual difference of students and easy to handle. The visionary teacher can manage the diversity by respecting each student's interest and treated them as individual but not a number. Teach-student collaboration with ICT tools helps in pedagogical shifting and management of diversity in mathematics classes."

This characteristics told by my participant announced that he has strong belief on ICT integrate pedagogy to manage multicultural class. Teachers have hesitation to use ICT integrated pedagogy even though it is effective in mathematics class due to the lack of knowledge about it. The ICT can support each individual students to learn mathematics differently and effectively. As concerning on this fact, Ghosh, Hattangdi and Atonu, (2007) said "ICT increases the flexibility of delivering of education so that the learner can access knowledge anytime and from everywhere". The best ways to manage the multiculturalism in class are; a) Ask about your students' interests and experiences so you can know them as an individual rather than the members of a group. b) Encourage all students to respond each other's questions and comments, not just your own, to foster a sense of community. c) Provide guidelines for group discussions so as to create an environment where students will feel free to put their opinions. d) Don't ignore or single out students and never ask a student to act as a spokesperson for his/her group. In the same concept T1 expressed their ideas as; 
We face many problems to teach students in a multicultural class such as; language problem, content problem, level of understanding. Basically, the problems arises due to the multicultural classroom. There are two type of multiculturalism in our classes they are critical multiculturalism, and Liberal multiculturalism. We can manage the multiculturalism by supporting different cultures and intercultural students differently in a society. Also multiculturalism can be manage by managing cognitive model of difference to increase the level of understanding. The ICT integrated pedagogy can support the students in multiple perspectives but due to time constraints and geographical difficulties it is not effectively implemented in our classroom.

To realizing the importance of using ICT in mathematics class, teachers tries to use ICT tools in the classroom. But they feel two type of problems for the effective implementations of ICT. One of them is all the students who enroll in mathematics class are not familiar and practiced with ICT tools and techniques. The second is, students and teachers have little knowledge as well as misconception about use of ICT tools regarding as time constraints. ICT integrated pedagogy can enhance the greater collaboration between the pupils as it helps to increase students' motivation towards the teaching. Due to geographical difficulties and resource constraints, Nepalese educational institutions are unable to manage appropriate learning resources in classroom. This leads to demotivate students as well as teachers towards new dimension in teaching learning. Teachers and students are very much curious and optimist towards the use of ICT in mathematics classes but the limited resources is the main huddle for the effective implementations.

\section{Conclusion}

The multicultural issue in the present context is a global issue of socialization as people are settling in every corner of the world due to various reasons. Everywhere an individual wants to show his identity and Nepal cannot be exception for that. Beside this, Nepal has its own problem based on hierarchy of caste system. In addition to that there is a problem of religious, ethnical, political and geographical issues. Different teachers have different experiences in diverse class. The experience of teachers indicates that they are unable to include the voices and experiences of all students to prepare them for an intercultural society and workplace that helps to create opportunities to utilize their knowledge. In case of homogenous classroom, it is especially important to emphasize multiculturalism because the only exposure our students may change to other cultures is through the activities, books and lessons that we provide them with. In this context, the diversity management is very essential for teachers in their best performance. The best ways to manage the multicultural class are; ask about your students' interests and experiences so you can know them as individuals rather than the members of a group, Encourage students to respond to each other's questions and comments, not just your own, Provide guidelines for group discussions so as to create an environment where students will feel free to put their opinions, Don't ignore or single out students and Use ICT integrated pedagogy.

\section{References}

Bottomore, T. B. (1986). Sociology: A guide to problem and literature. Bombay: Blackie and Sons.

Cakmak, M. (2013). Learning from teaching experiences: Novice Teachers'Thoughts. 
Hacettepe Universitesi Journal of Education, 1, 55-67. Retrieved from:http://www.efdergi. hacettepe.edu.tr/yonetim/icerik/makaleler/279-published.pdf.

Cobb, P. (1994a). Constructivism in mathematics and science education. Educational Researcher,23(7),4.

Cobb, P. (1994b). Where is the mind? Constructivist and sociocultural perspectives on mathematical development. Educational Researcher, 23(7), 13-20

D’Ambrosio, U. (1985). Socio-cultural bases for mathematics education. Campinas, Brazil: University of Campinas.

Ember, C. E., Ember, M. \& Peregrine P. N. (2002). Anthropology: New Delhi: Pearson Education.

Gautam, K. P. (2007). Introduction to anthropology and sociology. Kathmandu: Oxford International Publication.

Ghosh, Hattangdi, A. \& Atonu (2007). Enhancing the quality and the accebility of the

Guba, E. G., \&Lincoln,Y. S .(2001). Guidelines and checklist for Constructivist .

Haralambos, M. and Heald, R. M. (2000). Sociology: Themes and perspective. New Delhi: Cambridge University Press.

Impact of ICT in education (2014). Retrieve from http:// www.becta.org

Jha, M. (1999). An introduction to anthropological thought. New Delhi: Vikash Publishing House.

Knopf, A. A. (1998). High points in anthropology: New York: Random House.

Macular, R. M. and Page, C. H. (20002). Society and introductory analysis. New Delhi: Replica Press Pvt. Ltd.

Mazur,B. (2010) Cultural diversity in organizational theory and practice; Journal of intercultural management vol2, No. 2, November 2010

Regmi, R. R. (2003). The essentials of sociology. Kathmandu: Buddha Academic Publishers. Slattery, M. (2003). Key ideas in sociology: Cheltenham: Nelson Thornes Ltd.

Shreevastava, A. R. N. (2005). Essentials of cultural anthropology: New Delhi: Prentice Hill.

Thomas, R. R.(1990). From affirmative action to affirming diversity; Harvard Business.

Wagner, D. ( 2002) Teaching Strategies in Multicultural Education. Retrieved from http:// csmstu01.csm.edu/st03/dwagner/multicultural_education.htm.

Webster L. \&Mertov, P. (2007). Using narrative inquiry as a research method an introduction to using critical event narrative analysis in research on learning and teaching. Milton Park, Abingdon: Routledge. 